\title{
Teachers Take Charge of Their Resilience Through Self-Study
}

\author{
Tim Buttler \\ Burman University \\ Holly Kay \\ Parkview Adventist Academy
}

\begin{abstract}
This research arises from serious concerns surrounding teaching sustainability, given the everyday challenges teachers face as they learn and thrive. Internationally, teacher recruitment and retention are in crisis. COVID-19 has added to previous workloads resulting in many teachers describing their teaching experience as detrimental to their commitment, well-being, and health. This paper examines one teacher's professional development efforts to promote her resilience via self-study research methodology. The findings suggest that an intentional focus on developing resilience through self-study positively impacted teaching practices. As a result, the authors suggest that teachers take charge of their resilience by conducting their own self-study.
\end{abstract}

Keywords: resilience, self-study, professional development, self-care, teaching

\section{INTRODUCTION}

Nationally and internationally, teacher recruitment and retention are experiencing a crisis (Ainsworth \& Oldfield, 2019). In Canada, we know that between $40 \%$ and $50 \%$ of teachers leave the profession in the first five years of service (Schaefer, Long, \& Clandinin, 2012). Teacher attrition research indicates many reasons teachers leave the profession (Vagi, Pivovarova, \& Barnard, 2019), including the unique pressures and stresses that teachers experience. Many teachers describe workloads that detrimentally affect their commitment, well-being, and health and inhibit an acceptable work-life balance (Day \& Gu, 2007).

In the face of these concerns, some educational researchers have concentrated on teacher resilience as a pathway to promoting teachers' well-being (Day, Edwards, Griffiths, \& Gu, 2011). Recent work suggests that resilience facilitates healthy distress tolerance (Schussler et al., 2018), allowing teachers to cope with the increasing demands of teaching (Day, Christopher, 2008).

Resilience is defined in many ways. Beltman, Mansfield, and Price (2011) describe teacher resilience as "a dynamic process or outcome that is the result of interaction over time between a person and the environment," while others focus on the "attainment of positive adaptation within the context of significant adversity" (Cicchetti, 2010, p. 145). In this article, we use Cicchetti's definition as we examine how one high school teacher sought to build her resilience in the face of a dynamic and stressful teaching environment.

Multiple risk factors and protective factors impact teacher resilience (Beltman et al., 2011). Many of these factors are beyond the teacher's control; therefore, within this study, we focus on individual factors 
that teachers can control. Specifically, we examine the protective factor of self-care. As described in the Appendix, Holly, a high school teacher, accepted the responsibility for her well-being and sought to build supportive relationships within her personal and professional contexts by conducting a self-study. She then carried out a program of self-care as a form of professional development. Holly describes how she worked to promote her resilience by altering her diet (Owen \& Corfe, 2017), exercise (Craft \& Perna, 2004; Owen $\&$ Corfe, 2017), and sleep schedule (Sagaspe et al., 2006). In effect, she sought to build her resilience by altering her general well-being, which affected her job satisfaction and capacity to sustain motivation. Her overall goal was to provide a productive learning environment for her students.

Teacher professional development (PD) is one strategy many organizations use to improve teaching practice, yet the results are frequently disappointing (Opfer \& Pedder, 2011). Typically, these programs ignore the professional knowledge teachers bring into the PD experience (Timperley \& Alton-Lee, 2008). Calls for PD are not new; in the early '80, Schön (1983) noted a general crisis of confidence in occupations claiming professional status. For example, Schön believed that one must first recognize the importance of the individual practitioner's thoughts and actions (practice) concerning knowledge developed through research (theory). Timperley and Alton-Lee (2008) suggest that PD experiences often overlook this connection.

What would happen if, instead of traditional PD where teachers' professional knowledge is overlooked, teachers were encouraged to study their personal, professional dilemmas? How might this support student learning? There is a great deal of discussion regarding teaching quality, yet little discussion about how to encourage teachers to take charge of their PD (Samaras \& Roberts, 2011).

Instead of the top-down application of PD, how would the motivation for PD change if teachers were encouraged to explore personal issues? Samaras and Roberts (2011) suggest that effective change begins "when teachers pose purposeful and applicable questions about their practice that empower a reform change in the first person" (p. 42). Self-study research provides this type of endeavor. In our case study, Holly chose this innovative model of PD as she became a teacher-researcher. The question Holly sought to answer was whether intentional attention to self-care would increase her resilience.

\section{SELF-STUDY RESEARCH}

At its core, self-study teacher research "is designed to encourage teachers to be agents of their own reform initiatives while working collaboratively with school colleagues" (Samaras \& Roberts, 2011, p. 43). Therefore, self-study research is ideal for those examining personal steps towards change.

As self-study continues to mature as an option for teachers, multiple perspectives have emerged (LaBoskey, 2004). Noting these various perspectives, we chose to follow Samaras's (2011) work, which has been "gleaned, refined and extended from almost two decades of work by self-study scholars" (p. 70). Although self-study research is fluid and recursive, it is built around five main steps.

Holly's use of the self-study framework to build her resilience is described in the next section. As you read her research process, think about your teaching practices, and ask yourself whether self-study is suitable for you.

\section{PRACTICING SELF-STUDY TEACHER RESEARCH}

\section{First: Uncover Your Inquiry}

This type of study originates from the teacher-researcher's questions, situated in their particular context (Samaras \& Freese, 2006). The tensions, dilemmas, or crises are specific to their classroom; therefore, the observations and experiences are very personal. This personalized PD provides for increased intrinsic motivation when compared to traditional PD avenues.

Before her study, Holly identified that the increasing stress originating from her teaching context had begun to impact her significantly. The administration of her school was transitioning between school

districts. Would the new district administrators maintain the teaching philosophy of the current district administrators? Would her teaching position become redundant when her school district merged with 
another? Holly's dilemma was personal; work stress was affecting her personal and professional life. She decided to take charge. She sought to develop a more robust individual resilience through self-care.

\section{Second: Develop a Collaborative Team}

A defining feature of self-study research is critical collaboration. Regardless of the appearance of individualism that the term self-study initially presents, it is a challenge to develop an understanding of how one thinks and acts independently of others (Loughran \& Berry, 2005). A compelling study must include others - students, critical friends, or colleagues - to check data, interpretations, situations, and/or conclusions. This process also allows the teacher-researcher to step outside themselves and develop new insights. The discussions with critical friends enable the researcher to see perspectives that can challenge and strengthen their practice.

Within this study, Holly included three critical friends, who were people she trusted. They understood the context of her endeavor, provided specific feedback, asked provocative questions, and offered critiques to improve her self-care and thus fortify her resilience.

\section{Third: Seek Improved Learning}

Stemming from the desire for improved learning, self-study teachers often question the status quo in education. Nevertheless, they focus on specific issues, for example, personal teaching practices. Therefore, self-study teachers seek change, not the reproduction of the past. Fundamentally, self-study teachers care about understanding and improving their practice, with the ultimate goal of impacting student learning.

Holly sought to build her teaching resilience. Although this is a personal change, self-care increases resilience, thus impacting her interactions with students and improving her teaching practices. It is important to note that education literature consistently suggests a connection between a teacher's wellbeing and student learning (Gray, Wilcox, \& Nordstokke, 2017).

\section{Fourth: Design a Systematic and Transparent Research Process}

Although the findings may be believable, to build validity and quality in the research outcomes, "we must have good reasons to trust them to be true" (Feldman, 2003, p. 26). Multiple critical friends and additional authors help to facilitate transparency. A transparent process, which clearly and accurately records the research process through discussion and critique, improves the researcher's findings as well as builds credibility in the reader.

Holly gathered around her three critical friends and a second author. Each of these people helped to focus her at several stages of her inquiry. For example, her teaching colleague encouraged her at points when her exercise consistency declined, and her co-author encouraged her to write when she might have procrastinated.

\section{Fifth: Generate and Present Your Findings}

Self-study teachers do not view personal improvement as the last step in the research process. By making their learning public, self-study teacher-researchers advise and advance the education community as a whole. Presentations and publications allow the teaching community an opportunity to review and critique the generated knowledge.

This article is a significant way in which Holly's findings will be disseminated. Personally, improving one's professional environment is a substantial achievement, yet encouraging others to enhance their situations is possible only through diligent efforts to communicate one's journey. Finally, Holly has indicated plans to use her research findings as she enters her new role as a school administrator. Her new commitment to self-care will impact her communication with her colleagues and the evaluation of the teachers she works with. 


\section{IS SELF-STUDY RIGHT FOR YOU?}

As a personal, fluid concept, self-study is many things to many people (Ping, Schellings, \& Beijaar, 2018). A self-study teacher identifies their own questions based on their specific needs and context. For example, during her study, Holly sought an answer to whether self-care could increase her resilience and, consequently, improve her teaching practice. Self-study is a form of research that is ideal for those examining steps towards change.

The five steps described above are not a recipe that dictates a teacher's actions. Each self-study is distinct, as are each teacher's questions and desire for improvement. Holly's situation and issues are uniquely hers; thus, her application of self-study is uniquely hers. If you choose to conduct a self-study, your process will also be uniquely yours.

As a teacher, you might prefer pragmatic approaches to problems. You might ask, what if I embark on a self-study journey and it does not uncover the answers I seek? Those who have conducted this type of research and revealed unexpected findings (Buttler, 2020) argue that even if the study does not have the intended impact, the critical examination will not be devoid of learning. "Often, the questions teachers raise challenge their own ways of doing things" (Samaras \& Roberts, 2011, p. 45). The teacher-researcher inevitably develops new insights regarding their professional practice.

\section{FINAL COMMENTS}

Within the teacher resilience literature, the impact of self-care is currently underexamined (Beltman et al., 2011). However, self-care is a critical factor promoting a teacher's feeling of well-being (Ainsworth \& Oldfield, 2019). In Holly's study, she found that as she began to fortify her resilience, her professional life began to recover, and, consequently, her teaching practices improved.

Although resilience impacts each teacher's job satisfaction, well-being, and potential for burnout (Ainsworth \& Oldfield, 2019), one must be careful when assigning responsibility for resilience. By focusing only on the variable of self-care, one might mistakenly assume that resilience is the sole responsibility of teachers themselves. We agree with Johnson and Down (2013) that the tendency toward "hyperindividualisation" (p. 81) should be resisted when examining teacher resilience, as contextual variables significantly impact teacher resilience. The school environment affects a teacher's chances of thriving during adversity as much as their personal efforts (Cicchetti, 2010). Therefore, although this paper focuses on Holly's approach to building resilience, recent resilience literature stresses the importance of the teaching environment, including the school culture (Day, 2014). Building resilience requires both sides of the equation to be accounted for (Price, Mansfield, \& McConney, 2012).

In conclusion, Holly has shared her experience, allowing you to scrutinize the process and information she uncovered in the hope that you will choose to incorporate a measure of self-study into your classroom. We hope that this examination's positive impact on her may encourage others to take charge of their resilience.

\section{REFERENCES}

Ainsworth, S., \& Oldfield, J. (2019). Quantifying teacher resilience: Context matters. Teaching and Teacher Education, 82, 117-128. https://doi.org/10.1016/j.tate.2019.03.012

Beltman, S., Mansfield, C., \& Price, A. (2011). Thriving not just surviving: A review of research on teacher resilience. Educational Research Review, 6(3), 185-207. https://doi.org/10.1016/j.edurev.2011.09.001

Buttler, T. (2020). Disrupting my teaching practices: A teacher educator living as a contradiction. Studying Teacher Education, 16(2), 1-18. https://doi.org/10.1080/17425964.2020.1758654

Cicchetti, D. (2010). Resilience under conditions of extreme stress: A multilevel perspective. World Psychiatry, 9(3), 145. https://doi.org/10.1002/j.2051-5545.2010.tb00297.x 
Day, C. (2008). Committed for life? variations in teachers' work, lives and effectiveness. Journal of Educational Change, 9(3), 243-260. https://doi.org/10.1007/s10833-007-9054-6

Day, C. (2014). Resilient principals in challenging schools: The courage and costs of conviction. Teachers and Teaching, 20(5), 638-654. https://doi.org/10.1080/13540602.2014.937959

Day, C., \& Gu, Q. (2007). Variations in the conditions for teachers' professional learning and development: Sustaining commitment and effectiveness over a career. Oxford Review of Education, 33(4), 423-443.

Day, C., Edwards, C., Griffiths, A., \& Gu, Q. (2011). Beyond survival: Teachers and resilience. Nottingham, England: University of Nottingham.

Feldman, A. (2003). Validity and quality in self-study. Educational Researcher, 32(3), 26-28. https://doi.org/10.3102/0013189X032003026

Gray, C., Wilcox, G., \& Nordstokke, D. (2017). Teacher mental health, school climate, inclusive education and student learning: A review. Canadian Psychology, 58(3), 203-210. https://doi.org/10.1037/cap0000117

Johnson, B., \& Down, B. (2013). Critically re-conceptualising early career teacher resilience. Discourse: Studies in the Cultural Politics of Education, 34(5), 703-715. https://doi.org/10.1080/01596306.2013.728365

LaBoskey, V. (2004). The methodology of self-study and its theoretical underpinnings. In J. Loughran, M. Hamilton, V. LaBoskey, \& T. Russell (Eds.), International handbook of self-study of teaching and teacher education practices (pp. 817-869). Springer. https://doi.org/10.1007/978-1-40206545-3 21

Loughran, J., \& Berry, A. (2005). Modelling by teacher educators. Teaching and Teacher Education, 21(2), 193-203. https://doi.org/10.1016/j.tate.2004.12.005

Opfer, V.D., \& Pedder, D. (2011). Conceptualizing teacher professional learning. Review of Educational Research, 81(3), 376-407. https://doi.org/10.3102/0034654311413609

Owen, L., \& Corfe, B. (2017). The role of diet and nutrition on mental health and wellbeing. Proceedings of the Nutrition Society, 76(4), 425-426. https://doi.org/10.1017/S0029665117001057

Ping, C., Schellings, G., \& Beijaar, D. (2018). Teacher educators' professional learning: A literature review. Teaching and Teacher Education, (75), 93-104. doi:10.1016/j.tate.2018.06.003

Price, A., Mansfield, C., \& McConney, A. (2012). Considering 'teacher resilience' from critical discourse and labour process theory perspectives. British Journal of Sociology of Education, 33(1), 81-95. https://doi.org/10.1080/01425692.2011.614748

Sagaspe, P., Sanchez-Ortuno, M., Charles, A., Taillard, J., Valtat, C., Bioulac, B., \& Philip, P. (2006). Effects of sleep deprivation on color-word, emotional, and specific stroop interference and on self-reported anxiety. Brain and Cognition, 60(1), 76-87. https://doi.org/10.1016/j.bandc.2005.10.001

Samaras, A. (2011). Self-study teacher research: Improving your practice through collaborative inquiry. Los Angeles: SAGE.

Samaras, A., \& Freese, A. (2006). Self-study of teaching practices. New York: Peter Lang.

Samaras, A., \& Roberts, L. (2011). Flying solo: Teachers take charge of their learning through self-study research. The Learning Professional, 32(5), 42-45.

Schaefer, L., Long, J., \& Clandinin, J. (2012). Questioning the research on early career teacher attrition and retention. Alberta Journal of Educational Research, 58(1), 106-121.

Schön, D.A. (1983). The reflective practitioner: How professionals think in action. New York: Basic books.

Schussler, D.L., Greenberg, M., DeWeese, A., Rasheed, D., DeMauro, A., Jennings, P.A., \& Brown, J. (2018). Stress and release: Case studies of teacher resilience following a mindfulness-based intervention. American Journal of Education, 125(1), 1-28.

Timperley, H., \& Alton-Lee, A. (2008). Reframing teacher professional learning: An alternative policy approach to strengthening valued outcomes for diverse learners. Review of Research in Education, 32(1), 328-369. https://doi.org/10.3102/0091732X07308968 
Vagi, R., Pivovarova, M., \& Barnard, W.M. (2019). Keeping our best? A survival analysis examining a measure of preservice teacher quality and teacher attrition. Journal of Teacher Education, 70(2), 115-127. https://doi.org/10.1177/0022487117725025

\section{APPENDIX: HOLLY'S 2020 Research}

\section{Context}

I am a high school teacher in a school with eight teachers and 80 students. Our school has a great staff and student culture and is by far my favorite place to work. It's never been difficult to go to work until recently. Our school is changing governance, and last week, we were all technically laid off...all of us. Every. Single. Teacher. We are awaiting contracts from our new governing body, but to say we are stressed would be an understatement. This process was first announced over two years ago with the accompanying dismissal of our well-loved principal. Over this school year, five staff members will be laid off after this school year - two teachers and two dormitory deans. On top of those, we have another staff member retiring and another relocating. To say we are in a season of change is an understatement. And then COVID hit. This year will go down in history for more than one reason. To say everyone is tense is an understatement. We are hobbling our way through this wretched school year with a desperate attempt to recover whatever we can for the sake of our students.

So how does stress impact my teaching? Is it possible to counteract this in a manageable way? We learn that "self-care" is so important to educators, but it often just becomes another thing added to the list of essential items that don't get accomplished... and the stress grows. Is it possible that even a small amount of exercise could be enough to combat the effects of stress on our teaching practice?

\section{Step 1: Author Your Own Question}

The question I sought to answer through my self-study: "Will intentional attention to self-care increase my resilience?" I am taking a closer look at my interactions with my students, relationships with co-workers, and overall capacity for the volume associated with this profession and position.

\section{Step 2: Work With a Critical Friends Team}

For this research project, I collaborated with a teacher friend from a sister school, a colleague, and my husband. When my teacher friend heard about what I was doing, she asked if she could participate too! So we compared notes along the way. My colleague's job was to evaluate my overall positivity, energy level, and student relationships. My husband's job was to assess my general attitude about my situation. Am I more optimistic? Am I more willing to go to work? Am I speaking positively or negatively about my students?

\section{Step 3: Plan New Pedagogies for Improved Learning}

Why is this valuable to you? As fellow teachers, we all deal with stress to some degree or another. Stress causes us to become less effective, less conscious, and more prone to emotions and frustrations. If we can find a simple way to make you a better version of yourself, then there is value inherently built into this study.

Not going to lie; I was skeptical. After a couple of weeks of walking, I didn't think it was making any difference at all. Then I stopped. Good grief, was I floored by the difference it made. I was exhausted, irritable, and uninspired. Impacting my teaching practice was a natural by-product as I was less able to joke around with my students, found myself harping on their behavior more, and struggling to stay objective in my grading. As an art teacher, this is incredibly difficult when you are actually in a good headspace and even more so when you are miserable, tired, and feeling ineffective. I caught myself, mid-conversation, a few times thinking, "Why do I care so much about this insignificant thing?"

So then I decided, as any good researcher, that I needed to do this again to see if it was for real. So, I connected with my critical friends' group again, restarted the exercise and other self-care strategies, and started tracking its impact. 


\section{Step 4: Enact, Document, and Assess Your Research Process}

So what did I do? I made an intentional effort to exercise three times a week for at least 20 minutes each time. I started seeing my counselor again regularly. I started drinking more water; I cut out caffeine entirely and started reading again. These actions may seem like an extensive list of things to do, but for me, it was what I needed to do.

I'll admit the documentation aspect of this was difficult. How do you quantify feelings? I feel better, so something must be working. I kept my cool in situations where I justifiably could have lost it. My mind was clear, and I was able to handle some extremely challenging conversations with grace and wisdom. I could shield my colleagues from an onslaught of frustrations and unnecessary difficulties due to a mental fortitude that I previously lacked. I was able to continue teaching when everything about this job changed overnight. Somehow, in situations I would have once fallen apart, I am ok.

I made time to contemplate the results of my self-care each week. At these times, when available, I asked my critical friends for input. I periodically recorded these observations. My research process was less than perfect, but for me, the impact on my ability to do my job was real and continues to influence my priorities going forward.

\section{Step 5: Generate and Share What You've Learned}

Throughout this process, I've been in conversation with my critical friends and the co-author of this article. We've processed how this impacts me, my teaching, and the best way to present our findings to the educational community. Recently, I joined the administration team of my school, and as my role is changing yet again, these findings will color my leadership and evaluation of the teachers I work with. Are you taking care of yourself? Are you spending the time necessary to be your best self, so you come to school with the best possible attitude knowing this colors our interactions, experiences, and relationships? All are questions I will ask myself and my colleagues in the years to come.

As I step forward in my career, these findings are a constant reminder to take care of myself and make sure I am taking the steps necessary to face the uncertain world in which we now exist. Education is changing, and that impact is felt on us teachers. This exercise reminds me that to adapt to this change, to be the resilient force necessary to ride the tides of change and maneuver them to my favor, I need to take care of myself first.

I also see value in enacting self-study opportunities for my colleagues on a school-wide basis. Requesting our teachers to take a moment to evaluate their practices and check-in to make sure they are taking care of themselves could be a vital step in the whole school's success. If our teachers are healthy, supported, and prosperous, maybe our schools will be too.

\section{Conclusion}

In conclusion, previously, I had not connected my health and my success as a teacher. I knew it on a cognitive level but never experienced it on a practical one. Self-care is such a catchphrase these days, but connecting it with my resilience and my ability to navigate one of the most challenging years of my career thus far has been extremely valuable. COVID rocked our world and made it difficult to connect with my critical friends' group, but looking back over the last three months, I'm humbled by what I've accomplished and how healthy and resilient I feel about it all. It's been tough, but I'm ok, and I know most of that feeling comes from making sure I was taking care of myself throughout the process.

As you, dear teacher, read this, I hope you too will ask yourself these questions and determine the steps you need to take to ensure you are the best teacher you can be. 